\title{
10 health stories that mattered: Nov. 15-21
}

- Canada needs a national seniors' strategy to address patient gridlock in hospitals, which are "toxic" environments for patients with "chronic but not acute disease," according to CMA President Dr. Chris Simpson. Hospitals are "warehousing seniors" at $\$ 1000$ a day, compared to $\$ 130$ for long-term care and $\$ 55$ for home care.

- More than $80 \%$ of the 2500 youth admitted to hospital last year for selfharm injuries are girls, according to the Canadian Institute for Health Information. The rate of admission for self-harm for girls has increased $102 \%$ over the past five years. Boys account for two-thirds of the roughly 500 youth hospitalized following assault each year, though the rate for boys has decreased $34 \%$ over the past five years and the rate for girls has increased $22 \%$.

- The pharmaceutical company Apotex alleges in a lawsuit that Health Canada's ban on drugs from its facilities in India is illegal and politically motivated, reports the Toronto Star. The company is asking that the ban be lifted, is seeking reimbursement for losses and is requesting that Health Minister Rona Ambrose retract statements justifying the ban.
- A clinical trial for the Ebola vaccine developed in Winnipeg will take place in Halifax. The Canadian Center for Vaccinology is seeking 40 healthy adults for the randomized, double-blind, placebocontrolled study to test the efficacy and safety of the experimental BPSC1001 vaccine.

- An 11-year-old girl with acute lymphoblastic leukemia from a First Nations community cannot be forced by a hospital to undergo chemotherapy, ruled an Ontario judge. Despite physician opinion that the girl would not survive without conventional medical therapy, the judge ruled that the mother's decision to instead pursue traditional Aboriginal medicine was a constitutional right.

- The Toronto Board of Health is exploring possible measures to restrict children and youth from purchasing energy drinks. The Canadian Beverage Association opposed the initiative, suggesting energy drinks are safe for both adults and youth.

- Blue Cross has denied a claim from a Saskatchewan mother who received a bill for nearly $\$ 1$ million after unexpectedly giving birth while on vacation in the United States. The woman purchased travel insurance before the trip, but Blue Cross cited a pre-existing condition (hemorrhage from bladder infection when she was four months pregnant) in denying the claim.

- The influenza season has begun in Alberta and has caused 69 hospitalizations and seven deaths so far, according to Alberta Health Services. The province, which has already administered nearly a million doses of the flu vaccine, is urging all Albertans to get vaccinated.

- Two-thirds of doctors in the Regina area failed to follow regional handwashing rules before treating patients, reports CBC News. Several hospitals in the region had noncompliance rates exceeding $90 \%$ among all health care staff.

- The ALS Ice Bucket Challenge raised \$16.2 million in Canada from 260000 donors, announced ALS Canada. ALS societies across the country will invest $\$ 10$ million in research and \$6 million in programs to support Canadians living with the disease. - Roger Collier, CMAJ

CMAJ 2015. DOI:10.1503/cmaj.109-4948 